Session 3563

\title{
Teaching Factory
}

\author{
Sema E. Alptekin, \\ Reza Pouraghabagher, Patricia McQuaid, and Dan Waldorf \\ Cal Poly - San Luis Obispo
}

\section{Introduction}

Academia must develop a new approach to teaching in order to better prepare engineering students to function efficiently and adjust readily within the framework of the factories in the real world. Some engineering programs emphasize theory, while others emphasize application as isolated blocks. The "Teaching Factory" being developed at Cal Poly combines both theory and applications. It makes use of state-of-the-art industrial grade production equipment, computer hardware and software in the form of the following two systems: 1) a functioning "real" factory hardware environment, and 2) a Production Planning and Control Center.

The overall objectives of the Teaching Factory are:

- to graduate better professionals by providing leading edge concepts in modern manufacturing, enabling them to effectively compete in today's industry

- to enhance the current curriculum that will focus on modern manufacturing concepts

- to demonstrate viable solutions to the dynamics of technological challenges across the entire integrated business enterprise

- to transfer technology and information from and to partner companies as well as local companies, with student activities, team projects and senior projects as the primary vehicle.

The existing manufacturing facilities, including the metal removal, casting, rapid prototyping and electronics manufacturing laboratories of Cal Poly, provide the "real" factory hardware environment. A Production Planning and Control Center is being developed to provide the decision making and communication functions required in the modern factory. These two systems will function as an integrated whole by utilizing state of the art communication networks. The Teaching Factory will not eliminate traditional lessons, but rather will supplement them by providing an integrative framework to link courses throughout the curriculum. Furthermore, and whenever necessary, it will seek academic expertise from the College of Business to incorporate the analysis of costing, accounting, and financial aspects of our integrated approach to teaching. 
A Manufacturing Consortium has recently been established to provide additional funds in support of the Teaching Factory objectives. With help from industry and other agencies, Cal Poly's ABET accredited Manufacturing Engineering curriculum will be reengineered to include new laboratory experiments and real-world case studies that will provide the realism of modern manufacturing concepts to better prepare students for the challenges in industry today and into the 21 st century.

The basic concept of the Teaching Factory and progress to date are presented in the following sections. More information on various ongoing projects can be found at the Teaching Factory web site $^{1}$. Examples of other efforts in developing similar educational environments can be found in literature ${ }^{2-5}$.

\section{Teaching Factory Concept}

In order to better prepare Cal Poly graduates to manage the manufacturing systems of the 21st century, we plan to replicate a small-scale manufacturing factory, the Teaching Factory, to enable us to educate Cal Poly students in the most effective and realistic manner. This objective, of course, is in line with the "hands-on" philosophy of education at Cal Poly.

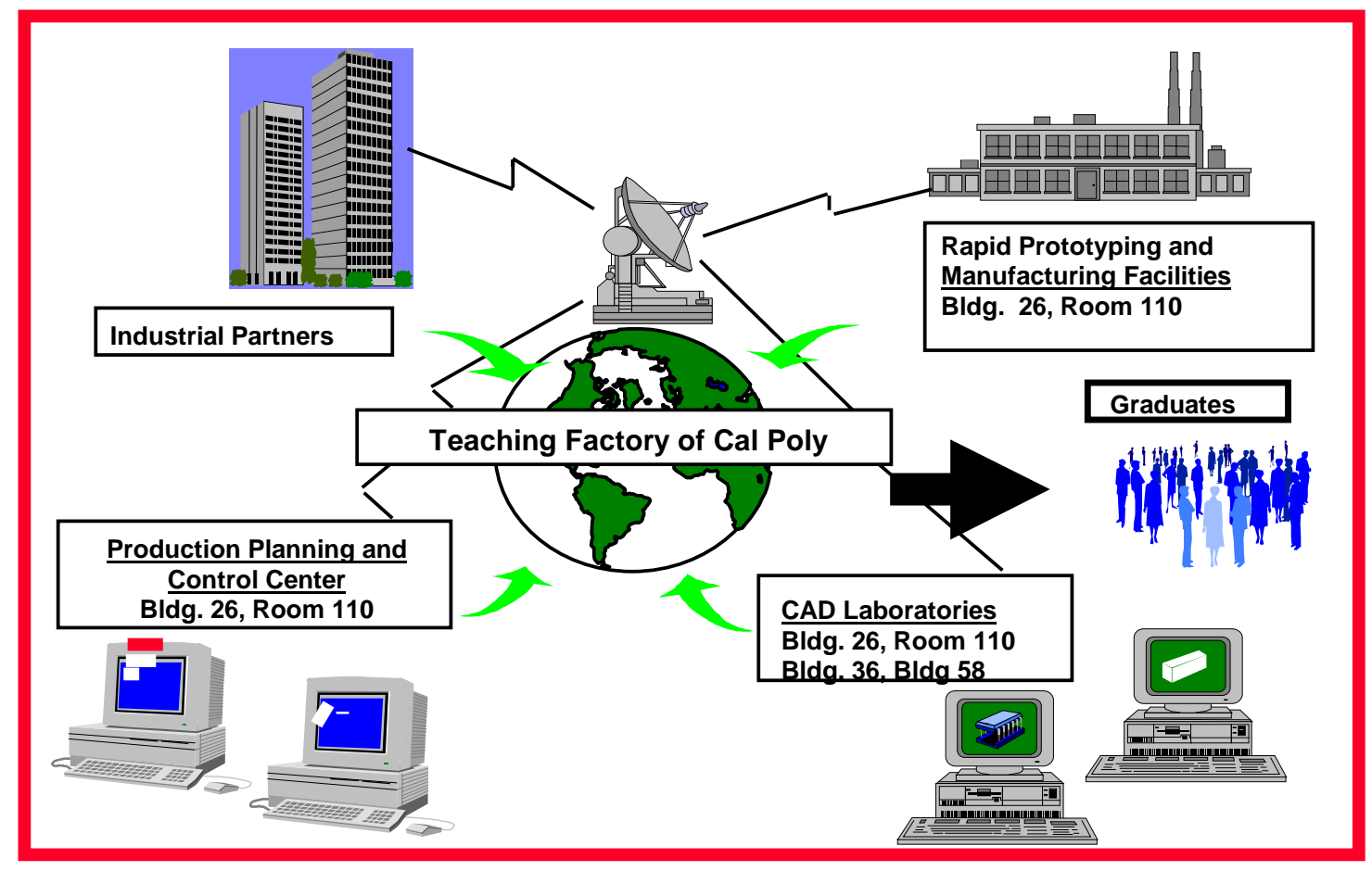

Figure 1. Teaching Factory Concept

The Teaching Factory will have dual purposes. One is to enable students to develop small-scale industrial products or consumer goods. The development will involve creating a prototype, 
reviewing various aspects of mass manufacturing, and verifying the suitability and feasibility of relevant design parameters using the hardware of the Teaching Factory. The second purpose is to provide tools for the planning and controlling of the required manufacturing operations for building small quantities of the verified designs. For this objective, a Production Planning and Control Center will be developed to simulate customer-order entries, design specifications, quantity, cost, and delivery contract agreements. In-house developed software modules will use the existing engineering database to plan all the material requirements for fabrication by the required time period. Students will follow the computerized plans and initiate the manufacturing operations. They then enter the order completion, scrap parts, and other operational data back to the database. Performance measures will be developed to check the original plans against the actual data obtained by students. Reports will be provided to the instructors, who will act as supervisors, to discuss accomplishments, or recommend corrective actions, if needed.

A typical scenario in this Teaching Factory is as follows: students in our first Computer-Aided Manufacturing course will design a new product using Computer-Aided-Design (CAD) labs and then fabricate the product using rapid prototyping. Dimensional data obtained from the prototype will be made available to the designers for design validation and verification. Once the prototype is approved, its relevant design and manufacturing data will be added to the database of the Teaching Factory. The production control team in IME 410/IME 411 (Inventory Control Systems/ Production Systems Analysis) will develop production schedules to produce the right quantity of products on time. Basic components of these products will be manufactured in the Teaching Factory by freshmen IME, EE, and ME students as they learn the principles of metal removal, casting, and electronics manufacturing in the introductory level manufacturing engineering courses such as IME 141 (Mfg. Processes: Net Shape), IME 143 (Mfg Processes: Material Removal), and IME 157 (Electronic Manufacturing).

\section{Accomplishments to date}

The Teaching Factory makes use of state-of-the-art industrial grade production equipment, computer hardware, and software. The major accomplishments are listed below:

- Several new laboratories were developed as part of the real system. A design studio with 20 computers and an adjacent briefing area are our first accomplishments. This project motivated us to reconfigure existing academic space to meet the needs of new teaching and learning models.

- A communications network was established to integrate several existing manufacturing laboratories with the Computer Aided Design, rapid prototyping, and Production Planning and Control Center.

- Development of a Material Requirements Planning package was undertaken by a group of interdisciplinary students participating in a pilot implementation of Teaching Factory activities (see Section IV).

- New courses were developed and offered (IME 428 Engineering Metrology, IMEX470 Supply Chain Management, IME 526 Advanced Topics in Manufacturing System Design). 
- Five Master's theses and senior projects that were dedicated to the development of the Teaching Factory were initiated and some were completed.

- Faculty members from both Colleges of Engineering and Business worked together to direct the development of several projects.

- Our industrial partners -- Epicor, IBM, HAAS, Chesapeake Supply Chain Division, Kiran Consulting, and Accenture, formerly Andersen Consulting provided state-of-the-art software and equipment, case studies, technical support, cash, and engineering time to assure the success of this project.

○ Epicor (Material Requirements Planning package donation and faculty training, valued at $\$ 24,200)$

- IBM (Automation line with robots, vision systems, conveyor belts, and controllers, valued at $\$ 1,000,000)$,

○ Kiran Consulting (Scheduling package --valued at \$50,000; industrial case studies for Supply Chain Management and Simulation; Engineering time),

- Accenture (Engineering time).

- A web site was developed to document several of these projects. Readers are encouraged to visit http://virtual.ime.calpoly.edu/vf// to find more about the details of our accomplishments.

\section{Pilot Implementation of Teaching Factory in Graduate IME Course}

One of the major activities of the Teaching Factory project took place in an experimental class in the Industrial and Manufacturing Engineering (IME) Department. In IME 526, Advanced Topics in Manufacturing System Design, 12 graduate students from varied disciplines (Industrial Engineering, Integrated Technology Management, and Engineering Management Program) were formed into teams to test the feasibility and the proof of concept for an operational Teaching Factory. Three IME faculty members, one computer network specialist staff, and a Management Information Systems faculty from the College of Business provided needed guidance for successful completion of the project.

Teams of students proposed independent plans for designing and fabricating a batch of a simple product. The faculty advisors finalized the type of product to be manufactured within the project's time limit. The approved product was an aluminum key chain/coin holder combination (Figure 2). It was a typical industrial product in that it required purchased items, machining, and assembly operations.

The students designed, prototyped, and ran production on the product. Students gained hands-on experience with CAD/CAM, DFM, and Design for Quality as the product was developed. Design decisions included the material, feature locations, and dimensional specifications. The finished product has four assembled components, a purchased fastener and purchased keychain ring and the two halves of the main body to be fabricated in-house. During prototype and tool design, the original design was modified several times to ensure ease of manufacture and prevention of processing defects. Students also designed and ran the processes of production. A total of 10 units of 
the product were manufactured by each group on a $\mathrm{CNC}$ vertical machining center using machine code generated by CAM software. Special fixtures were designed and fabricated to simplify the operation. Set-up and cycle times and instances of scrap and re-work were noted as they occurred on the shop floor. Throughout the production runs, the students were forced to deal with real-life scheduling problems such as machine down-time, raw material variations, and competition for machine time by other jobs.

The authors were involved in the project as the Industrial Engineering (IE) faculty advisors prepared the overall production plan, the Manufacturing Engineering (MfgE) faculty assisted the students in actual fabrication of the product, and the COB faculty assisted in the design of the communication link between the IME database and the accounting reports, including the general ledger, A/P, A/R, and payroll. In addition to the graduate students, two MIS undergraduate students assisted in the linkage between the IME database and the reporting software from the COB.
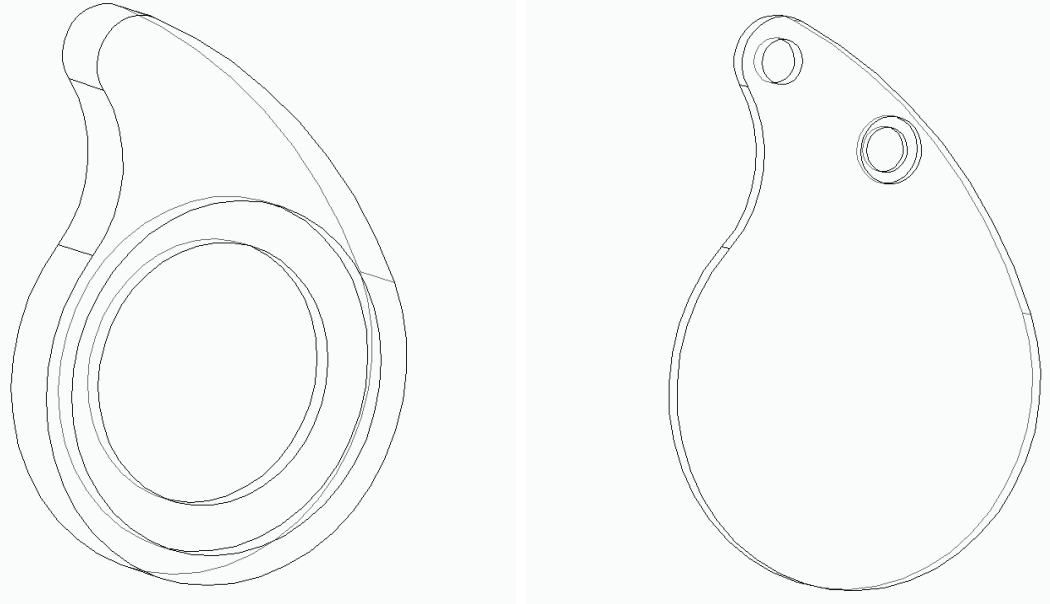

Figure 2. Key chain/coin holder combination (bottom and top)

Each team reported, by presentations and written reports, their final results to all faculty advisors who in turn evaluated the differences of approach among these competitive teams. Advantages and disadvantages of each approach were discussed and the final results were stored in the IME computer networks for the purpose of references for future projects.

In this project, we have successfully demonstrated the proof of concept for a Teaching Factory at Cal Poly. Furthermore, we have shown that the collaboration between the faculty and students in two Colleges - College of Engineering and College of Business, indeed resulted in a realistic concept of how actual business operations are planned and executed in the real world.

Both the engineering and business students learned much about designing information systems. They all learned that they needed to spend more time on the initial design and that the design of a system needs to incorporate components that they may not be familiar with. Both groups (engineering and business) learned to ask for help from the other groups when needed and learned such cooperation and integration are needed from the beginning. They learned that decisions to be 
made were not just an engineering or business decision, but were systems-integration decisions.

\section{Assessment}

Assessment of the success of the program takes the form of immediate results and longer-term monitoring. Various metrics are now being tracked as indicators of both. As for immediate results, the Teaching Factory objectives (listed above in Section I) are measured by the number of new courses introduced that deal with the Teaching Factory concepts of supply-chain, mass production information flow, and concept-to-product simulated factory (Objective 2: "Enhance the curriculum"); the number of Master's theses and senior projects involved in Teaching Factory activities and dedicated to studying these same issues (Objective 3: "Demonstrate viable solutions"); the number of industry gifts in the form of software and equipment and the number of presentations/reports made to industry partners (Objective 4: "Transfer technology from partner companies" and "to partner companies"). As indicated above, the introduction of 3 new courses, $\underline{5}$ Master's and senior projects, and 4 industry gifts shows significant immediate success in meeting the original goals of the project. Due to the ongoing completion of several aspects of the project, no presentations of results have yet been made to industry partners. The transfer of results back to industry (as oral or written reports), however, is planned as soon as current activities are completed. Also, because of the nature of the project's first objective "Graduate better professionals," no immediate results are applicable.

Longer-term assessment of the project objectives will involve continuing to track the metrics listed above and also collecting additional data within the scope of the continuous improvement efforts currently being implemented for the industrial and manufacturing engineering programs (with regards to ABET accreditation). A separate set of assessment data is being collected throughout each year to measure IE and MfgE program objectives, which have much in common with the first two Teaching Factory objectives stated above. Graduating seniors, alumni, alumni supervisors, faculty, and industrial advisors are all regularly surveyed to provide feedback on success of program objectives and outcomes such as "preparing students for immediate contribution to engineering practice" and providing students with "ability to use modern tools and technologies necessary for engineering practice," "ability to perform integrated systems design," "competence in computer systems and information technology," and of course "a learn-by-doing, hands-on education." These outcomes directly relate to the Teaching Factory objectives of graduating better professionals and enhancing the curriculum. The data will be collected and reviewed yearly, leading to faculty action whenever metrics show potential for improvement.

In addition to the above assessment measures, we still plan to invite the industry partners on campus to attend student project presentations. This will be an on-going iterative process among the parties involved with the feedback being constantly incorporated into the program. Both the relevancy of the material covered and the effectiveness of the teaching will be monitored and measured. An on-line feedback mechanism will be developed utilizing the web. The graduates will be asked to visit this home page and give feedback after they gain some experience in industry. We will constantly be 
seeking to identify any additional features that need to be included in the program.

\section{Manufacturing Consortium and Future Plans}

Partial support was provided by Cal Poly to initiate this project. We were able to build on our strong relationship with our industrial partners and form a Manufacturing Consortium in Fall 2000. Several leading manufacturing companies were eager to support our ongoing efforts. In order to leverage the industrial support, we developed a proposal in December 2000 seeking matching funds from the Society of Manufacturing Engineering (SME). A grant from SME's Education Foundation, if funded, would serve as the final gift, allowing for the complete implementation of our expanded outreach efforts, cutting-edge laboratories and updated coursework as early as Spring 2003. The involvement of California manufacturing industry leaders is crucial to the project's success, and their needs and advice will be particularly useful as the project progresses.

Success of the project will impact several aspects of regional manufacturing: the Manufacturing Engineering Program will be able to graduate a greater number of better-educated engineers; students from across California will have an attractive option for studying manufacturing engineering and establishing successful careers in the field; and finally, regional employers will find talented, enthusiastic graduates who are better-equipped to meet today's industry challenges and contribute to company success.

Bibliography

1. URL: http://virtual.ime.calpoly.edu/vf/

2. URL: http://wait.pspt.fi/english/default.htm

3. URL: http://bizednet.bris.ac.uk:8080/virtual/

4. URL: http://factory.isye.gatech.edu/index.htm

5. URL: http://www.usc.edu/dept/ise/research.html

\section{SEMA E. ALPTEKIN}

Dr. Sema Alptekin is a professor of the Industrial and Manufacturing Engineering Department at Cal Poly State University in San Luis Obispo. She has been serving as the department chair since 1997. Prior to joining Cal Poly, she was a faculty member at the University of Missouri-Rolla (UMR) for ten years. During this period she worked for the General Motors Corporation. Dr. Alptekin received a B.S. degree in Mechanical Engineering, an M.S. degree in Mechanical Engineering, and a Ph.D. in Industrial Engineering in 1981, all from Istanbul Technical University, Turkey.

\section{REZA POURAGHABAGHER}

Dr. Reza Pouraghabagher is a professor of Industrial and Manufacturing Engineering at Cal Poly State University. His areas of expertise are production and inventory planning/control, manufacturing systems analysis, and human factors of technology transfer. He has consulted with numerous companies in the U.S. and Canada. He received his Ph.D. in 
Industrial Engineering from the University of Iowa in 1976.

\section{PATRICIA MCQUAID}

Dr. McQuaid is an associate professor in the College of Business-MIS at Cal Poly State University in San Luis Obispo. She has taught a wide range of courses in both the Colleges of Business and Engineering at several universities, and has industry experience in manufacturing and banking. Dr. McQuaid earned a M.S. and Ph.D. degree in Computer Science and Engineering from Auburn University, an MBA from Eastern Michigan University, and a B.S. degree in accounting from Case-Western Reserve University. She is a Senior Member of the American Society for Quality.

\section{DAN WALDORF}

Dr. Daniel Waldorf is currently an assistant professor in the Industrial and Manufacturing Engineering Department at Cal Poly State University in San Luis Obispo. He received his B.S. and M.S. in Industrial Engineering and Ph.D. in Mechanical Engineering from the University of Illinois at Urbana-Champaign. Dan spent two years in industry as a Quality Engineer at a Midwest automotive parts manufacturer. He currently teaches several courses related to manufacturing processes and systems and performs research on problems in machining of metals. 